\title{
JUDICIALIZAÇÃO DAS POLÍTICAS PÚBLICAS DE SAÚDE: EFETIVAR DIREITOS SEM VIOLAR A ISONOMIA DOS ENTES FEDERATIVOS
}

\author{
JUDICIALIZATION OF PUBLIC HEALTH POLICIES: \\ EFFECTING RIGHTS WITHOUT VIOLATING THE ISONOMY \\ OF FEDERATIVE ENTITIES
}

ANDRÉ AUGUSTO SALVADOR BEZERRA Professor do PPGPD/Enfam. Mestre e doutor pela USP. Pesquisador em estágio pós-doutoral no Colaboratório de Desenvolvimento e Participação da USP. Juiz de direito do TJSP. https://orcid.org/0000-0002-3546-2016

FABIANE BORGES SARAIVA Mestranda do PPGPD/Enfam. Coordenadora do Comitê Regional de Saúde do CNJ, Região Centro/Rio Grande do Sul. Juíza de direito do TJRS. https://orcid.org/0000-0003-0482-3250

\section{RESUMO}

Este artigo traça um panorama da judicialização dos conflitos na área da saúde pública no Brasil, com foco na possibilidade de o fenômeno levar a uma quebra da isonomia entre os entes federativos, obstandoos na implementação de políticas aptas a efetivar direitos. O trabalho utiliza-se de revisão bibliográfica e de citações jurisprudenciais. Quanto a estas últimas, abordamos especialmente o Tema n. 793 do Supremo Tribunal Federal, que elidiu a lógica da solidariedade do direito privado na exigibilidade de políticas de saúde a todos os entes da Federação. Sustentamos que a consolidação desse entendimento indica um caminho possível para a efetivação do direito à saúde pela via judicial, pois considera a isonomia federativa e, consequentemente, reduz os impactos desestabilizadores causados pelo excesso de litigiosidade.

Palavras-chave: judicialização da saúde; SUS; isonomia; Tema n. 793, do STF; competência federativa. 


\section{ABSTRACT}

This article provides an overview of the judicialization of conflicts in public health in Brazil with a focus on the possibility that the phenomenon may lead to a break in isonomy among federal entities, preventing them from implementing policies capable of enforcing rights. The work uses bibliographic review and jurisprudential citations. As for the latter, we dealt especially with Theme 793 of the Supreme Federal Court, which eliminated the logic of the solidarity of private law trials for health policies for all entities of the Federation. We maintain that the consolidation of this understanding indicates a possible path for the realization of the right to health through the judicial system, since it considers federative equality and, consequently, reduces the destabilizing impacts caused by excessive litigation.

Keywords: health judicialization; SUS; isonomy; Theme n. 793, of the STF; federative competence.

Recebido: $26-5-2021$

Aprovado: 28-6-2021

\section{SUMÁRIO}

1 Introdução: contextualização do tema. 2 Judicialização das políticas públicas. 3 Panorama da judicialização da saúde a partir da pandemia da Aids. 4 O Tema n. 793 do STF. 5 Conclusão. Referências.

\section{INTRODUÇÃO: CONTEXTUALIZAÇÃO DO TEMA}

A soma de quase 80 milhões de processos que tramitam no Judiciário brasileiro, nos termos dos dados noticiados pelo Conselho Nacional de Justiça (2020), é suficiente para revelar que se vivencia, no Brasil, o fenômeno que Boaventura Santos (1986) intitula de explosão da litigiosidade.

De fato, quem vive o cotidiano forense, sobretudo os chamados operadores do direito, conhece bem a realidade de tribunais e varas judiciais abarrotados de processos, instaurados para a solução judicial de conflitos oriundos das mais diversas relações, públicas ou privadas, direta ou indiretamente reguladas pelos direitos consagrados na Constituição de 1988. No âmbito das relações controvertidas à espera de uma decisão 
judicial, estão aquelas que se relacionam a atuações do Estado que, conforme a concepção tradicional do princípio da separação de Poderes (art. $2^{\circ}$ da Constituição Federal), deveriam ser solucionadas pelo Poder Executivo.

Eis a base de outro fenômeno, o mais amplo da explosão da litigiosidade: "a judicialização das políticas públicas. Por políticas públicas, mencionamos os [...] programas de ação governamental visando coordenar os meios à disposição do Estado e as atividades privadas, para a realização de objetivos socialmente relevantes e politicamente determinados". (BUCCl, 2006, p. 38)

Não faltam exemplos que podem simbolizar a situação acima mencionada. Ordens judiciais para ampliação de vagas em creches, para a consideração das peculiaridades das formas de vida de populações tradicionais (indígenas e quilombolas) ou para o fornecimento de medicamentos gratuitos simbolizam a judicialização das políticas públicas enquanto fenômeno que nasceu da explosão da litigiosidade.

A intromissão judicial em práticas que, em princípio, deveriam ser de atribuição do Executivo, proporcionou ensejo a um terceiro fenômeno, ainda mais específico (mas inserido nos demais), que pode ser compreendido pelo derradeiro exemplo acima mencionado (as ordens para fornecimento de medicamentos), qual seja a judicialização da saúde pública.

A base jurídica de tal fenômeno encontra-se no art. 196 da Constituição?. O dispositivo define o que é e como exercer o direito à saúde, estabelece sua universalidade, gratuidade e integralidade, e, ainda, determina que a obrigação de concretizar esse desiderato é de todos os entes federados (dever do Estado como um todo): União, estados-membros, Distrito Federal e municípios. A amplitude do texto constitucional tem dado ensejo à propositura de milhares de ações judiciais, coletivas e individuais (estas, em sua enorme maioria), para se compelir os governos de todas as unidades federativas a promover políticas públicas objetivando a garantia do direito em questão.

A explosão da litigiosidade da saúde pública não foi reduzida nem mesmo com a atuação do Poder Legislativo federal que, no pós-

\footnotetext{
"A saúde é direito de todos e dever do Estado, garantido mediante políticas sociais e econômicas que visem à redução do risco de doença e de outros agravos e ao acesso universal e igualitário às ações e serviços para sua promoção, proteção e recuperação." (art. 196 da Constituição)
} 
Constituição de 1988, elaborou uma gama de diplomas normativos que estruturaram e organizaram o chamado Sistema Único de Saúde - SUS, o que, em princípio, proporcionaria concretude ao texto constitucional no que diz respeito às mais diversas atividades públicas relacionadas à saúde do brasileiro. Como aponta Maria Paula Dallari Bucci (2017), porém, o art. 196 da Constituição perdura, por si só, fundando múltiplas decisões judiciais que determinam o que o gestor público deve e o que o gestor público não deve fazer.

Um fenômeno de tão amplas proporções - a abalar todo o arcabouço secularmente construído em torno da separação das atribuições estatais executiva, legislativa e judicial em órgãos distintos e autônomos (art. 2ำ da Constituição Federal) - tem gerado discussões nos domínios da sociologia, da ciência política, da gestão de políticas públicas e, dentre outros, do direito. Neste último, de um lado, há uma perspectiva que salienta que a busca pelo Judiciário para a intervenção em políticas públicas evidencia o exercício da cidadania, tal como o faz Paulo Eduardo Alves da Silva (2019, p. 448), no sentido de que "do ponto de vista da sociedade, complementarmente, o quadro de volume de processos nos tribunais sugere simplesmente que a população aprendera a utilizar um dos mais importantes instrumentos de cidadania que thes foi disponibilizado: a ação judicial". Por outro lado, há quem aponte que a leitura isolada do art. 196 da Constituição tem levado à tomada de decisões judiciais destituídas de critérios científicos em desfavor do Poder Público, tal como, a título de ilustração, em emblemático caso em que houve a concessão de mais de uma dezena de milhares de decisões judiciais, em reduzido espaço de tempo (2015-2016), contra a Universidade de São Paulo - USP, a fim de esta fornecer gratuitamente remédio apelidado de pílula do câncer, destituído, porém, de qualquer eficácia academicamente comprovada: "Amparados apenas no art. 196 da Constituição em sua crença na autoaplicabilidade dos direitos fundamentais, esse grande contingente de magistrados seguiu determinando, freneticamente [...] a entrega das cápsulas aos doentes. Parecia que a Justiça havia descoberto a cura do câncer". (BUCCl, 2017, p. 33)²

Realmente, é difícil elidir a afirmação que a busca do Judiciário por direitos constitucionalmente previstos configura importante sintoma de alvorecer da cidadania da população de um Estado, como o brasileiro,

\footnotetext{
${ }^{2}$ Conforme Bucci (2017), a chamada pílula do câncer não era registrada na Agência Nacional de Vigilância Sanitária - Anvisa, não tinha eficácia científica comprovada nem era considerada segura quanto à toxicidade. Existia, tão somente, uma dissertação de mestrado aprovada na USP, patenteada pelo docente orientador, cujo suposto poder de cura fora noticiado nas redes sociais.
} 
de passado prevalentemente autoritário. Da mesma forma que não se pode ignorar a preocupação por decisões judiciais que transpassam o saber científico para, a pretexto de se fazer cumprir um dispositivo da Constituição aplicado como absoluto e dissociado de outros dispositivos constitucionais, determinar políticas de fornecimento de todo e qualquer medicamento que apareça no mercado.

Há, por seu turno, outras preocupações que o fenômeno pode ensejar. Nesse aspecto, é preciso lembrar que somente há intromissão judicial em políticas de saúde porque parcela da população não se mostra satisfeita com as providências governamentais para a efetivação do art. 196 da Constituição. Dessa forma, a atuação do Judiciário viria para levar governos a cumprir tal dispositivo.

Em meio a milhões de processos judiciais que tramitam ou que tramitaram em torno do tema, é possível, entretanto, vislumbrar a possibilidade de juízes, involuntariamente, obstarem as ações governamentais que poderiam efetivar direitos.

Vejamos o caso da estrutura federativa, inserida como base do Estado brasileiro pelo art 1ํ da Constituição. É inerente à ideia de Federação a igualdade jurídica entre cada um dos respectivos entes: no Brasil, têm-se União, estados-membros, Distrito Federal e municípios. Cada um dotado de igual autonomia para realização de políticas públicas que Ihe são constitucionalmente atribuídas. A opção descentralizadora foi aquela tida pelo legislador constituinte como a mais eficaz para a concretização de direitos por atuações governamentais. Trata-se de opção, a propósito, imodificável, por inserida entre as chamadas cláusulas pétreas (art. 60, § 4ํ․ da Constituição).

É possível, contudo, enxergar a intromissão judicial em políticas públicas de saúde como fator impeditivo ao funcionamento isonômico dos entes federativos. Grande parcela das ações que dão corpo ao fenômeno mais amplo da judicialização das políticas públicas são de natureza individual. Nos casos em que se discutem o direito à saúde, para agravar, têm-se ainda ações individuais que, fundadas na solidariedade das políticas públicas, dirigem-se indiscriminadamente a todas as unidades federativas. Daí, indagarmos: em nome do cumprimento do citado art. 196, é possível exigir o fornecimento de medicamento de alto custo a qualquer município, independentemente de sua dimensão populacional ou econômica? Em nome da solidariedade, prevista no 
mesmo dispositivo, um estado de menor recurso financeiro pode ser compelido a fornecer um mesmo tratamento consideravelmente dispendioso que um estado de Produto Interno Bruto - PIB mais elevado?

Tais questões, como vemos, sugerem que as respostas judiciais às demandas individuais que crescem exponencialmente, ano após ano, podem criar desequilíbrios financeiros entre os entes federados. Com isso, abala-se a igualdade entre eles. Consequentemente, abala-se a descentralização federativa, como visto, tida pela Constituição como meio eficaz de concretizar os direitos nela previstos. A efetividade dos próprios direitos é, então, também abalada. Tudo em nome de um único dispositivo constitucional, o art. 196.

Diante de todo o quadro descrito e das questões colocadas, pretendemos, com este artigo, examinar os fundamentos da judicialização da saúde, bem como a forma pela qual o fenômeno ostenta o potencial de violar a igualdade entre os entes federativos que, em princípio, deveria nortear as políticas públicas realizáveis para implementação de direitos. Para isso, fazemos uso de pesquisa bibliográfica que se soma à citação de decisões judiciais, proporcionando-se, neste último ponto, atenção especial ao relativamente recente ato decisório do Supremo Tribunal Federal - STF que declarou a competência concorrente dos entes federados para efetivar o direito à saúde. Sustentamos que, com tal entendimento, a corte que representa o ápice do Judiciário brasileiro apontou um caminho para a efetivação do direito à saúde, pela via judicial, sem ferir a isonomia entre União, estados-membros, Distrito Federal e municípios, de modo a diminuir os impactos desestabilizadores causados pelo excesso de litigiosidade.

Em que pese a judicialização da saúde ser tema exaustivamente analisado no âmbito acadêmico, este artigo inova ao acrescentar ao debate o tema da violação da igualdade federativa a partir de um entendimento manifestado pelo STF. A compreensão do fenômeno está longe de ser superada, merecendo constantes e atualizadas análises.

Coerentemente aos objetivos e à relevância acima expostas, dividimos 0 artigo em quatro outras seções, para além dessa contextualização introdutória. Na seção seguinte (esta é a seção 1), descrevemos como a Constituição de 1988 ensejou maior intercâmbio entre a política e o direito, fator que, somado à incapacidade do Poder Público brasileiro em efetivar os direitos, fomentou a apreciação de políticas públicas pelo Judiciário. Na seção 2, analisamos a forma pela qual tal maior intercâmbio colaborou para a intensa judicialização da 
saúde pública que sucede no Brasil. Na seção seguinte, consideramos o problema da quebra da isonomia entre os entes federativos advindo do fenômeno em questão e, ao final, os possíveis impactos a serem gerados pelo Tema n. 793 do STF. Na derradeira seção, apresentamos nossas conclusões.

\section{JUDICIALIZAÇÃO DAS POLÍTICAS PÚBLICAS}

Embora a judicialização das políticas públicas, vigente no contexto maior do fenômeno da explosão da litigiosidade, ainda gere críticas pautadas em uma concepção positivista do princípio da separação de Poderes, como o faz com notável rigor metodológico Elival da Silva Ramos $(2015)^{3}$, na prática cotidiana estatal nem sempre é fácil distinguir as matérias políticas de incumbência do Executivo e do Legislativo das matérias jurídicas de competência do Judiciário.

De fato, o Estado, na realização de suas tarefas de mediar as múltiplas demandas sociais, tem o direito como ferramenta apta a materializar os objetivos políticos estampados no ordenamento jurídico. Trata-se, como se vê, de desafio interdisciplinar, a alcançar, inexoravelmente, as políticas públicas:

Não obstante, definir as políticas públicas como campo de estudo jurídico é um movimento que faz parte de uma abertura do direito para a interdisciplinaridade. Alguns institutos e categorias jurídicas tradicionais, hoje despidos de seu sentido legitimador original, buscam novo sentido ou nova força, restabelecendo contato com outras áreas do conhecimento, das quais vinha se apartando desde a caminhada positivista que se iniciou no século XIX. (BUCCI, 2006, p. 2)

Dessa forma, "o Estado contemporâneo caracteriza-se por uma mudança política direcionada para a sociedade e pela sua intervenção no que diz respeito ao domínio econômico e social" (CUSTÓDIO; DABULL,

\footnotetext{
3 Para o autor (RAMOS, 2015, posição 4926), o elevado estágio de intromissão judicial em questões políticas requer, como resposta necessária, uma volta renovada às bases do positivismo jurídico kelseniano, a fim de, segundo suas palavras: "[...] propiciar o ajuste ótimo entre a criatividade inerente à jurisdição constitucional (lato sensu) e o indispensável acatamento aos princípios do Estado de Direito, dentre eles o da separação de poderes, impedindo que o voluntarismo bem intencionado, mas institucionalmente desastroso, dos órgãos judiciários acabe por solapar um dos fundamentos mais caros de qualquer democracia: o respeito à soberania popular e à participação política que dela decorre."
} 
2013, p. 15). Exige-se, pois, intervenção da realidade estatal para tornar possível a efetivação das normas constitucionais, através da compreensão da necessidade de delimitar o papel do direito na construção e na manutenção das políticas públicas.

Repare-se, de tais observações, os estreitos vínculos entre os campos político e jurídico. A Política é o locus da elaboração de práticas e sistemas que deverão atender aos interesses de determinada área pública, atenta à questão do planejamento, que envolve a criação de expectativas atingíveis, gerenciando, contemplando e arbitrando diferentes necessidades e interesses dos responsáveis e destinatários do resultado de atuação do Poder Público. Ao direito, por seu turno, cabe transformar tais objetivos e expectativas em lei, formalizando e determinando o modo de execução e de fiscalização das metas políticas.

Em suma,

A ação do Estado por políticas se faz vinculada a direitos
previamente estabelecidos ou a metas compatíveis
com os princípios e objetivos constitucionais, de forma
que, ainda quando aqueles a serem beneficiados não
tenham um direito a certo benefício, a provisão deste
benefício contribui para a implementação de um
objetivo coletivo da comunidade política. (ARZABE,
2006, p. 54)

A vigente Constituição trouxe, consigo, um intercâmbio, ainda maior, de ambos os campos. Filiada aos movimentos constitucionalistas originados na Europa Ocidental no pós-Segunda Guerra Mundial (século $X X)$ que, superando o liberalismo ortodoxo dos primeiros tempos do Estado de Direito (séculos XVIII e XIX), atribuíram ao Estado a realização de múltiplas tarefas, objetivando reduzir as desigualdades inerentes ao funcionamento de uma economia de mercado, a Carta brasileira de 1988 revelou-se eminentemente detalhista e rica na definição de direitos sociais concretizáveis por políticas públicas. Dessa influência, a maior chegada de questões políticas ao Poder de Estado, como visto, dotado, em tese, da atribuição de examinar conflitos sob a ótica jurídica, o Judiciário.

O fenômeno da judicialização das políticas públicas não chega a ser, portanto, um fato surpreendente. Na verdade, trata-se de fenômeno fomentado pelo próprio texto constitucional:

A extensão e a complexidade dos direitos sociais garantidos, bem como o grau de detalhamento combinados com a capacidade do Judiciário de 
exercer o controle de constitucionalidade de leis e atos normativos, propiciaram um aumento substancial das áreas de intervenção e atuação pública deste poder. A Lei Maior conferiu capacidade aos magistrados e às cortes judiciais de produzirem impactos sobre o processo de decisão política. Em decorrência, a Constituição transforma-se em um texto programático, operando-se um estreitamento da margem de manobra dos políticos e, consequentemente, ampliando-se o papel político do Judiciário. (SADEK, 2004, p. 81)

Corroborando para esse processo, tem-se o fato de os amplos direitos constitucionalmente previstos não terem logrado do Estado brasileiro, ao menos a curto prazo, a promoção de políticas públicas capazes de superar antigos problemas sociais e econômicos do país. Na realidade, a vigência do documento de 1988 "[...] fez eclodir uma distância colossal entre a realidade das normas jurídicas e a realidade da vida da população, em muito empobrecida com as políticas ditatoriais que pareciam superadas" (BEZERRA, 2016). O Judiciário passou, então, a ser procurado pela população para reduzir aludido distanciamento e, em tais termos, efetivar as normas jurídicas em vigor.

Caso ilustrativo da forma pela qual o Poder Judiciário ingressa no campo da implementação de políticas públicas encontra-se na decisão paradigmática do Recurso Extraordinário n. 592.581, na qual o Supremo Tribunal Federal determinou a execução de obras em unidades prisionais para garantir os direitos fundamentais dos cidadãos sob custódia do Estado. Na ocasião, o Relator Ministro Ricardo Lewandowski acolheu a proposta demandada para prescrever a seguinte tese de repercussão geral:

É lícito ao Judiciário impor à administração pública obrigação de fazer, consistente na promoção de medidas ou na execução de obras emergenciais em estabelecimentos prisionais para dar efetividade ao postulado da dignidade da pessoa humana e assegurar aos detentos o respeito à sua integridade física e moral, nos termos do que preceitua o artigo 5, XLIX, da Constituição Federal, não sendo oponível à decisão o argumento da reserva do possível nem o princípio da separação dos poderes. (BRASIL, 2015)

Lembramos ainda que, conforme definição inserida nas linhas introdutórias deste texto, as políticas públicas não configuram ações que se encerram em um único ato. Há, nestas, enquanto programas de 
governo, um caráter processual, que, conforme Maria Paula Dallari Bucci (2002, p. 192) auxilia no impulso da, cada vez mais frequente, atuação judicial sobre opções governamentais:

A própria existência da chamada "judicialização da política" é um fator que por si demonstra a processualidade das políticas públicas, na medida em que maior número de conflitos sociais passa a ser submetido à lógica processual, submetendo ao Poder Judiciário, uma vez que o modelo jurídico da Constituição favorece a admissão do conflito, e não sua rejeição. O processo judicial vem-se modernizando e atualizando, não apenas no Brasil, de modo a buscar corresponder ao anseio social. São exemplos disso os processos coletivos, a abertura ao tratamento dos interesses difusos e coletivos, a adoção das tecnologias de informação e comunicação, e uma série de inovações processuais e procedimentais que decorrem da litigiosidade de massa, isto é, a ampliação das formas de acesso à justiça e, ligado a isso, o aumento da importância social dessas formas de solução de controvérsias, em busca de maior amplitude e eficácia.

Há, contudo, de se ter em conta - e, aqui, a preocupação dos críticos do fenômeno é absolutamente pertinente - que um número excessivo de decisões judiciais individuais, sem que se considere a organização e o planejamento das políticas públicas, é apta a gerar um desequilíbrio incontornável. Os casos de determinações judiciais para fornecimento gratuito de medicamentos pelo Estado são elucidativos. A gigantesca repetição de demandas individuais em torno de tal escopo terminou por se tornar um fator de desorganização da atuação estatal, em detrimento de regras essenciais para o uso racional do erário, como regrado pela legislação infraconstitucional em diversos diplomas normativos, inclusive aqueles que regem as licitações.

Tal descontrole envolve também a questão referente aos destinatários das ordens judiciais. Nas últimas décadas, presenciamos determinações de juízes dirigidas aos mais diversos entes federativos, sem que se saiba ao certo quem é o efetivo responsável pelas medidas. Por vezes, a destinatária é a União, por vezes os estados-membros, o Distrito Federal ou os municípios, sem qualquer critério claro, mas aparentemente fundada na solidariedade constitucionalmente estabelecida para as ações de saúde. 
É de se notar, porém, que a própria Constituição traz, em seu conteúdo, instrumentos que visam obrigar os gestores a realizar prestações que tragam resultados de caráter mais igualitário e planejado, como a atuação do Ministério Público ou da Defensoria Pública em sede de Ação Civil Pública. Trata-se de alternativa efetiva ao ingresso de ações individuais para cada paciente que, por exemplo, tenha internação recusada administrativamente ou não receba medicamento que deveria ser fornecido gratuitamente a toda a população.

A utilização adequada de tais instrumentos configura uma necessidade para um fenômeno que, de um lado, parece inevitável e, de outro, ostenta potencial de desorganizar a gestão pública. Lembramos que as demandas objetivando a intromissão judicial sobre políticas públicas de saúde tiveram um aumento de 130\% em 10 anos, sem que necessariamente houvesse melhora na prestação dos respectivos serviços. (CONSELHO NACIONAL DE JUSTIÇA; INSPER, 2019)

\section{PANORAMA DA JUDICIALIZAÇÃO DA SAÚDE A PARTIR DA PANDEMIA DA AIDS}

Como vemos do exemplo dos medicamentos, a judicialização da saúde ganha contornos peculiares no âmbito do fenômeno mais amplo da judicialização das políticas públicas. Os seus fortes impactos para a administração pública, na forma acima mencionada, geram maior curiosidade acadêmica sobre o tema, o qual, para ser adequadamente compreendido, impõe que discorramos, ainda que brevemente, sobre suas origens e sua dinâmica atual.

Nesse sentido, a intensa judicialização ganhou corpo no Brasil sob uma pandemia. Não a vivida no atual século XXI, trazida pelo vírus SARSCoV-2, causador da Covid-19. Mas a pandemia do final do século XX, originada pelo vírus HIV (Human Immunodeficiency Virus), causador da Síndrome de Imunodeficiência Adquirida, também conhecida pela sua sigla em inglês, Aids (Acquired Immunodeficiency Syndrome).

O impacto da doença foi mundial e atingiu inúmeros setores da sociedade, proporcionando ensejo a debates sobre sexualidade, proteção de vulneráveis, discriminação e hábitos sociais. Até hoje, não foi encontrada uma vacina que a evite, estando no continente africano o maior número de pessoas infectadas pelo vírus. Durante a década de 1980, a corrida para descobrir um imunizante ou um medicamento tomou 
contornos drásticos, pois o diagnóstico era uma sentença para uma morte dolorosa, em definhamento, combinada com a cruel característica de ser uma doença que poderia ser assintomática por muito tempo, tornando impossível saber quem portava o patógeno mortal.

A conquista científica da fabricação do chamado coquetel de medicamentos que proporcionava longevidade e, com o tempo, uma vida praticamente igual à de uma pessoa não portadora, levou a uma justificada esperança para os atingidos pela moléstia. Todavia, no período, os governos federal e estaduais brasileiros inicialmente não fizeram uso dessa inovação científica, insistindo em medicamentos destituídos de maior eficácia contra a doença.

A situação começou a alterar-se com a intromissão do Judiciário no tema. Consoante estudo publicado pelo Ministério da Saúde (BRASIL, 2005), marco de suma importância no processo sucedeu quando, em 1996, a assessoria jurídica do Grupo de Apoio à Prevenção à Aids - Gapa ingressou judicialmente, contra o Estado de São Paulo, com pedido de fornecimento do referido coquetel em favor da professora e ativista da luta contra a doença, alegando que aqueles que lhes eram entregues pela Secretaria de Estado de Saúde (AZT e o ddl) não produziam efeitos. O juízo da 1a Vara da Fazenda Pública de São Paulo acolheu, liminarmente, o pedido para determinar a mudança de medicamento a ser fornecido, tido cientificamente como mais eficaz que aqueles disponibilizados pelo Poder Público.

O sucesso obtido pela autora da ação judicial levou a uma enxurrada de novas ações judiciais. Calcula-se que, entre os anos de 1991 e 1998, os processos ajuizados em favor de portadores de Aids abrangiam 90\% do conjunto de ações em que se discutiam atuações estatais sobre a saúde (VENTURA; SIMAS; PEPE; SCHRAMM, 2010). Os reflexos desse quadro alcançaram o Poder Legislativo. Conforme referido estudo do Ministério da Saúde, "em novembro de 1996, após mobilização da Sociedade e da Coordenação Nacional de Aids, o Congresso Nacional aprovou a Lei n. 9.313, do Senador José Sarney, que obrigava o Estado a fornecer os medicamentos antiaids". (BRASIL, 2005, p. 25)

O restante da história é conhecido. O Brasil passou a ocupar a vanguarda no atendimento dos pacientes com Aids, atuando na informação da população sobre como evitar a contaminação e fornecendo teste grátis para qualquer pessoa. Além disso, agiu, rigorosamente, com as companhias farmacêuticas que produziam os antirretrovirais para que o preço permitisse a distribuição gratuita. 
Como percebemos, a intromissão judicial em favor de portadores de Aids não levou a uma desorganização das políticas públicas. Pelo contrário, auxiliou na concretização da universalidade, gratuidade e integralidade do cuidado da saúde da população como previstos no ordenamento jurídico. Tudo porque os demais poderes se viram constrangidos a criar uma política pública de distribuição gratuita de medicamentos. Daí que, em 2000, o fornecimento de medicamento para enfermos com Aids representava apenas 14,6\% das ações que discutiam atuações estatais sobre a saúde. (VENTURA; SIMAS; PEPE; SCHRAMM, 2010)

Havia, de todo o narrado, uma expectativa pela diminuição da interferência do Poder Judiciário no campo da saúde. Não foi, entretanto, o que ocorreu. Pelo contrário, reforçou-se, judicialmente, a aplicabilidade do art. 196 da Constituição, que, de norma programática passa paulatinamente a ser reconhecido pelo Judiciário como norma constitucional de plena eficácia: as ações (individuais e coletivas) encaminhadas à Justiça, buscando a obtenção de bens e serviços de saúde, têm a quase totalidade dos pedidos deferidos pelos magistrados.

Nesse quadro, a simbólica decisão do STF, relatada pelo Ministro Celso de Mello, consolidando o entendimento favorável a determinações, pelo Judiciário, de fornecimento gratuito de medicamentos:

O caráter programático da regra inscrita no art. 196 da Carta Política - que tem por destinatário todos os entes políticos que compõem, no plano institucional, a organização federativa do Estado brasileiro - não pode converter-se em promessa constitucional inconsequente, sob pena de o Poder Público, fraudando justas expectativas nele depositadas pela coletividade, substituir, de maneira ilegítima, o cumprimento de seu impostergável dever, por um gesto irresponsável de infidelidade governamental ao que determina a própria Lei Fundamental do Estado. (BRASIL, 2000)

Como adiantado na introdução, nem mesmo o progresso legislativo em termos de organização do SUS foi suficiente para barrar a intensidade da judicialização: a edição da Lei n. 8.090, de 13 de novembro de 1990, por exemplo, nada alterou neste sentido. Também não foram suficientes a criação de órgãos de gestão, descentralização e coordenação de políticas públicas, como a Comissão Nacional de Incorporação de Tecnologias no Sistema Único de Saúde - Conitec. 
A litigância judicial perdurou ampliando-se continuamente, o que foi fomentado pelo próprio STF. No julgamento do pedido de Suspensão de Tutela Antecipada n. 175 (STA 175), relatada pelo Ministro Gilmar Mendes, em 2010, a Corte validou a solidariedade irrestrita entre União, estados-membros, Distrito Federal e municípios na promoção de políticas públicas de saúde (BRASIL, 2010). O art. 196 da Constituição seria, então, exigivel de qualquer ente da Federação, irrestritamente.

\section{O TEMA N. 793 DO STF}

No atual ponto da exposição, retornamos às perguntas formuladas na introdução desta pesquisa: é possível exigir o fornecimento de medicamento de alto custo a qualquer município, independentemente de sua dimensão populacional ou econômica? Em nome da solidariedade, um Estado de menor recurso financeiro pode ser compelido a fornecer um mesmo tratamento consideravelmente dispendioso que um estado de Produto Interno Bruto - PIB mais elevado? E agora acrescentamos mais uma questão: em que medida a solidariedade irrestrita impacta no cotidiano de cada entidade federada em seu trabalho de concretizar direitos?

Todas essas preocupações, colocadas em forma de questionamento, podem agora ser, ao menos, atenuadas a partir de novo entendimento trazido pelo STF. Com efeito, em Sessão Plenária realizada em 22 de maio de 2019, sob a relatoria para o acórdão do Ministro Edson Fachin (Embargos Declaratórios ao Recurso Extraordinário n. 855.178/Sergipe), a Corte fixou a chamada tese do Tema n. 793, assim ementada:

CONSTITUCIONAL E ADMINISTRATIVO. EMBARGOS DE DECLARAÇÃO EM RECURSO EXTRAORDINÁRIO COM REPERCUSSÃO GERAL RECONHECIDA. AUSÊNCIA DE OMISSÃO, CONTRADICCÃO OU OBSCURIDADE. DESENVOLVIMENTO DO PROCEDENTE. POSSIBILIDADE. RESPONSABILIDADE DE SOLIDÁRIA NAS DEMANDAS PRESTACIONAIS NA ÁREA DA SAÚDE. DESPROVIMENTO DOS EMBARGOS DE DECLARAÇÃO. 1. É da jurisprudência do Supremo Tribunal Federal que o tratamento médico adequado aos necessitados se insere no rol dos deveres do Estado, porquanto responsabilidade solidária dos entes federados. O polo passivo pode ser composto por qualquer um deles, isoladamente ou conjuntamente. 2. A fim de otimizar a compensação entre os entes federados, compete à autoridade judicial, diante 
dos critérios constitucionais de descentralização e hierarquização, direcionar, caso a caso, o cumprimento conforme as regras de repartição de competências e determinar o ressarcimento a quem suportou o ônus financeiro. 3. As ações que demandem fornecimento de medicamentos sem registro na Anvisa deverão necessariamente ser propostas em face da União. Precedente específico: RE 657.718, Rel. Min. Alexandre de Moraes. 4. Embargos de declaração desprovidos. (BRASIL, 2019)

Como vemos, extrai-se que a ratio decidendi da fixação da tese do Tema n. 793 é de que a solidariedade prevista no art. 23, inciso II, da Constituição Federal não pode ser lida à luz da solidariedade do direito civil. A solidariedade constitucional entre os entes federativos nas políticas de saúde pública configura a possibilidade de, nos termos do voto do Ministro Edson Fachin,

[...] incluir outro ente no polo passivo, como responsável pela obrigação, para ampliar sua garantia, como decorrência da adoção da tese da solidariedade pelo devergeral de prestar saúde. [...]; iv) Se o entelegalmente responsável pelo financiamento da obrigação principal não compuser o polo passivo da relação jurídico processual, sua inclusão deverá ser levada a efeito pelo órgão julgador, ainda que isso signifique deslocamento de competência; v) Se a pretensão veicular pedido de tratamento, procedimento, material ou medicamento não incluído nas políticas públicas (em todas as suas hipóteses), a União necessariamente comporá o polo passivo, considerando que o Ministério da Saúde detém competência para a incorporação, exclusão ou alteração de novos medicamentos, produtos, procedimentos, bem como constituição ou a alteração de protocolo clínico ou de diretriz terapêutica (art. 19-Q, Lei n. 8.080/1990), de modo que recai sobre ela o dever de indicar o motivo da não padronização e eventualmente iniciar o procedimento de análise de inclusão, nos termos da fundamentação. (BRASIL, 2019)

Por fim, no mesmo voto, complementa o referido Ministro:

O texto, em sua primeira parte, reafirma a solidariedade e, ao mesmo tempo, atribui poder-dever à autoridade judicial para direcionar o cumprimento. A tese não 
trata da formação do polo passivo. Caso se direcione e depois se alegue que, por alguma circunstância, o atendimento da demanda da cidadania possa ter levado um ente da Federação a eventual ônus excessivo, a autoridade judicial determinará o ressarcimento a quem suportou o ônus financeiro. (BRASIL, 2019)

Acrescentando ao raciocínio do relator, cabe apontar que o financiamento de medicamentos no SUS segue a lógica da complexidade do tratamento da doença, da garantia da integralidade do tratamento por meio de linhas de cuidado e da manutenção da racionalidade financeira entre as esferas de gestão do SUS. Desconsiderar essa forma de atribuição de responsabilidade coloca em risco a própria manutenção do sistema e o equilíbrio das contas públicas.

No Item 2 da tese fixada em julgamento com repercussão geral, explicita-se que existe, por parte do ente pagador que não tem responsabilidade administrativa pela prestação alcançada, o direito à compensação de valores, e que, para a sua otimização, a autoridade judicial deve direcionar o cumprimento para que haja ressarcimento ao ente que arcou com a responsabilidade de outrem. Portanto, diz quem direciona qual decisão e para qual finalidade.

Parece, pois, cristalino que a circunstância que motivou o julgador a tratar da questão da repartição de responsabilidades, regra constitucionalmente prevista e concretizada na Lei n. 8.090/1990, foi o desequilíbrio orçamentário causado pela solidariedade das obrigações relacionadas à saúde pública quando somada à massiva judicialização.

Conforme analisado no voto, as leis que operacionalizaram os princípios constitucionais da descentralização e da hierarquização do Sistema Público de Saúde foram posteriores à primeira afirmação da solidariedade dos entes, que ocorreu no julgamento da STA n. 175. A situação em que foi estabelecida a solidariedade irrestrita entre as unidades da Federação em muito difere da atual, possivelmente em razão das decisões judiciais proferidas nos últimos anos. A STA n. 175 tratou de ações que tinham por objeto prestação de saúde pelos entes federados, tendo, porém, sido proferida em momento anterior à vigência de leis que definiram a distribuição da competência administrativa do SUS.

Foi a partir dessas premissas que passaram a ser elaborados enunciados que procuram desenvolver o significado da solidariedade em questão. $O$ enunciado IV, por exemplo, estipula que "cabe ao órgão 
judiciário zelar para que o ente responsável administrativo esteja no polo passivo, mesmo que isso implique em mudança de competência". (BRASIL, 2019)

O relator do caso, de maneira pragmática, previu no que acarretaria a adoção da tese vencedora, considerando que a presença da União em qualquer dos polos de uma ação judicial necessariamente atrairia a demanda para competência da Justiça Federal: entendeu-se por bem esclarecer que caberia ao juiz cuidar do correto direcionamento do feito.

Nota-se que, mesmo antes do julgamento em exame, havia motivos lógicos, racionais e, o mais importante, justos, para uma interpretação da solidariedade inscrita no art. 196 da Constituição Federal, conforme as expectativas de quem arca com os desajustes cada vez mais visíveis do SUS. Não é o caso de se desconsiderar a necessidade que o cidadão tem de procurar a Justiça, visto que nela está o seu último socorro para a concretização de seus direitos e garantias constitucionais; trata-se de considerar que a judicialização, antes de ser fator de maior desorganização administrativa e orçamentária, pode ser causa impulsionadora de melhorias, como efetivamente foi em inúmeras ocasiões (lembremos o caso da judicialização de medicamentos de combate à Aids).

A decisão em exame, relatada pelo Ministro Fachin, ao mencionar a obrigação de o juiz direcionar a causa de forma a facilitar o ressarcimento de despesas com saúde, refere-se a algo diferente de nova ação de ressarcimento, prevista no ordenamento jurídico. Assim, a decisão vinculativa da Corte Suprema deixa claro que o ressarcimento ao ente pagador deve se dar no cumprimento da sentença exarada. $O$ corolário lógico de tal assertiva é pressupor a participação de todos os réus, sob pena de tornar inviável a aplicação da tese. Em outras palavras, a ação deverá tramitar, desde a fase postulatória, permitido o devido contraditório, com a participação do ente que, em tese, resistiu à pretensão do autor. Só assim será possibilitado cumprir a regra de competência prevista na Constituição Federal.

O exposto no Tema n. 793 do STF traz o equilíbrio esperado e previsto na repartição de competências sobre prestação em saúde pública para uma situação que é uma das grandes causadoras da judicialização excessiva, qual seja, os medicamentos não padronizados (INSPER, 2019). O exame atento dos institutos que compõem a ratio decidendi mostra que não se está negando a solidariedade da obrigação, mas determinando 
apenas à União a incorporação de protocolos e tratamentos que serão distribuídos pelo SUS e a necessidade de que tal ente federativo esteja no polo passivo em todas essas demandas.

Tudo isso se deve ao fato de que, desde a fixação da solidariedade por ocasião da STA n. 175, houve uma distorção da aplicação do instituto. Levou-se à situação em que, independentemente da divisão de atribuições previstas nas leis que organizam a política pública em saúde, todos os entes passaram a ter o dever de prestar qualquer obrigação sanitária, como se todos tivessem as mesmas estruturas sociais e econômicas, desconsiderando o fato de o Brasil ostentar a posição de um dos cinco países mais desiguais do mundo, inclusive em termos regionais. (ONU, 2017)

Trataram-se, pois, os entes federados sem considerar suas disparidades populacionais, sociais e econômicas, levando à quebra da isonomia entre eles. O resultado mais evidente foi o aumento exponencial da judicialização, que, por sua vez, levou ao aumento de gastos sem a correlata melhora ou aumento de oferta das prestações sanitárias.

Nesse sentido, estudo sobre o tema (SANTOS; TERRAZAS, 2014) revelou que os municípios, proporcionalmente, gastam muito mais de suas verbas em saúde do que os demais entes federados, permanecendo em situação desvantajosa em relação a estes: com efeito, os municípios gastaram em média $21,45 \%$ de seu orçamento, enquanto os estadosmembros investiram 12,69\% e a União, 3,9\%.

A distribuição de competências pactuadas no cabedal legislativo que estrutura o SUS existe para que todos os entes federados possam cumprir com as respectivas obrigações na implementação da política de saúde pública de acordo com suas possibilidades e dentro do equilíbrio orçamentário que todo gestor deve buscar. As ações judiciais, ao compelir qualquer ente a custear todo e quaisquer medicamentos e tratamentos que não estão sob sua responsabilidade, torna tal previsão constitucional letra morta. Tais investidas contribuem para a desestruturação do SUS:

A considerar-se a solidariedade vigorante em todas as ações, é possível que um mesmo indivíduo ajuíze três ações distintas, uma contra a União, outra contra o Estado ou Distrito Federal, e uma terceira contra o Município, em todas elas deduzindo a mesma pretensão. Como a orientação jurisprudencial fixou que não há litisconsórcio necessário, tampouco litispendência, ou mesmo conexão, então haverá três possibilidades 
de obter um mesmo provimento. Sem embargo do mérito da pretensão, mas partindo do pressuposto que um medicamento seja devido, então os três entes comprarão medicamentos para um mesmo paciente, havendo gasto indevido e desnecessário de recursos. (GEBRAN NETO; DRESCH, 2014, p. 2)

Cabe acrescentar que as políticas públicas tratam de áreas em que a atuação conjunta dos entes federados é indispensável. A divisão de atribuições não é prevista apenas no acesso ao direito à saúde, como se pode depreender do art. 23 da Constituição:

Como todas as esferas de governo são competentes, impõe-se que haja cooperação entre estas. Tendo em vista o "equilíbrio do desenvolvimento e do bemestar em âmbito nacional" (CF/88, art. 23, parágrafo único). A atribuição de competência comum não significa, porém, que o propósito da Constituição seja a superposição entre a atuação dos entes federados, como se todos detivessem competência irrestrita em relação a todas as questões. Isso, inevitavelmente, acarretaria a ineficiência na prestação dos serviços de saúde, com a mobilização de recursos federais, estaduais e municipais para realizar as mesmas tarefas. (BARROSO, 2008)

Ao decidir questões sanitárias em processos individuais, a visão global da política pública não existe por parte do julgador nem se espera que tal aconteça. Quando o Poder Judiciário interfere individualmente de forma pontual, excepcional, como deveria ser, o acesso à justiça não desequilibra o acesso à saúde. A fim de prestigiar o princípio da isonomia e o princípio constitucional do acesso universal e igualitário às ações e prestações de saúde, ao gestor deve ser propiciada a elaboração de políticas públicas que tornem a saúde pública digna e integral para todos os cidadãos. Isso ocorre quando a Constituição Federal e as leis infraconstitucionais que estruturam o Sistema Único de Saúde são cumpridas pelos gestores e reforçadas pelas decisões judiciais, como ocorreu na fixação do Tema n. 793. Ao fazê-lo, o Poder Judiciário traz isonomia ao cenário sanitário brasileiro, realizando de forma concreta o ideal de bem-estar social almejado na Constituição de 1988, quando insculpiu em seu texto os direitos sociais devidos aos cidadãos. 


\section{CONCLUSÃO}

Procuramos evidenciar, ao longo do texto, que a evolução do fenômeno da judicialização da saúde, ao ampliar ainda mais o fenômeno maior da explosão da litigiosidade brasileira, teve como marco inicial a pandemia da Aids. A partir de decisões judiciais que compeliram o Poder Público a fornecer gratuitamente medicamentos eficazes aos portadores do vírus HIV, verificou-se que a intromissão de juízes em políticas públicas objetivando proporcionar cumprimento ao art. 196 da Constituição poderia ser necessária.

O problema é que a evolução do tema não sucedeu de modo linear. Assim como tantos outros fenômenos que perduram por vários anos e, até mesmo, décadas, a luta social pela efetivação do direito à saúde pela via da judicialização foi submetida a idas e vindas ou a avanços e retrocessos. Do auxílio à população em fazer cumprir a Constituição, o Judiciário mostrou também, ainda que involuntariamente, potencialidade de obstar o cumprimento da mesma Constituição. Obstar, por exemplo, - funcionamento decentralizado da estrutura federativa, tida, pelo legislador constituinte, como meio gerencial imprescindivel para se alcançar os direitos que ele mesmo definiu.

Exigir igualitariamente, por intermédio de ações individuais, as mesmas políticas de saúde por parte de todos os entes federativos, em nome da solidariedade, significa ignorar as desiguais populações, as dimensões territoriais e os recursos financeiros de cada um deles. Significa tratar igualmente desiguais, a ponto de ampliar ainda mais as desigualdades, sem embargo de o art. 3으, inciso III, da Constituição determinar ser a redução das desigualdades regionais um dos objetivos do Estado brasileiro.

O entendimento fixado pelo STF, por intermédio do Tema n. 793, estabelece uma luz no fim do túnel para que a intensa intromissão judicial em políticas de saúde não atrapalhe, em vez de auxiliar, o direito em discussão. Estabelecer que a solidariedade entre as unidades da Federação não segue a mesma lógica da solidariedade do direito privado - isto é, de idêntica exigibilidade da prestação entre todos os devedores - significa respeitar as peculiaridades de cada uma delas, mantendo a igualdade federativa e consequentemente toda a racionalidade, na gestão de políticas públicas, consagrada na Constituição como caminho necessário para que os direitos não passem de promessas destituídas de concretude. 
Encerramos, então, nossas considerações, deixando anotado que este texto foi escrito durante a grande pandemia posterior à da Aids, a pandemia da Covid-19. A tragédia vivida das várias centenas de milhares de mortos no Brasil tem colocado à tona a necessidade de haver um sistema de saúde público eficiente e pautado no planejamento e na estratégia na alocação de recursos. Como alcançar esses objetivos com a pulverização de ações individuais dirigidas indiscriminadamente a todos os entes da Federação? 


\section{REFERÊNCIAS}

ARZABE, Patrícia Helena Massa. Direitos Humanos e políticas públicas. In: BUCCl, Maria Paula Dallari (org.). Políticas públicas: reflexões sobre o conceito jurídico. São Paulo: Saraiva, 2006.

BARROSO, Luís Roberto. Da falta de efetividade à judicialização excessiva: direito à saúde, fornecimento gratuito de medicamentos e parâmetros para a atuação judicial. Migalhas, São Paulo, 21 jan. 2008. Disponível em: https://www.migalhas.com.br/depeso/52582/ da-falta-de-efetividade-a-judicializacao-excessiva-direito-a-saude-fornecimento-gratuito-de-medicamentos-e-parametros-para-aatuacao-judicial. Acesso em: 24 maio 2021.

BEZERRA, Andre Augusto Salvador. Explosão da litigiosidade é resultado da distância entre lei e realidade. Consultor Jurídico, São Paulo, 5 nov. 2016. Disponível em: https://www.conjur.com.br/2016nov-05/andre-bezerra-litigiosidade-vem-distancia-entre-lei-realidade. Acesso em: 24 maio 2021.

BRASIL. Supremo Tribunal Federal. Agravo de Instrumento no Recurso Extraordinário n. 271.286-8. Rio Grande do Sul. 2a Turma. Relator: Min. Celso de Mello. Diário da Justiça, Brasília, 24 nov. 2000 .

BRASIL. Ministério da Saúde. Secretaria de Vigilância de Saúde. Programa Nacional de DST e Aids. O remédio via justiça: um estudo sobre o acesso a novos medicamentos e exames HIV/AIDS no Brasil por meio de ações judiciais. Brasília: Ministério da Saúde, 2005. Disponível em: http://bvsms.saude.gov.br/bvs/publicacoes/medic_justicaO1.pdf. Acesso em: 2 fev. 2021.

BRASIL. Supremo Tribunal Federal. Agravo Regimental na Suspensão de Tutela Antecipada n. 175 (STA 175). Ceará. Relator: Min. Gilmar Mendes. Diário da Justiça, Brasília, [17 mar.] 2010.

BRASIL. Supremo Tribunal Federal. Recurso Extraordinário n. 592581. Rio Grande do Sul. Tribunal Pleno. Relator: Min. Ricardo Lewandowski. Diário da Justiça, Brasília, [13 ago]. 2015. 
BRASIL. Supremo Tribunal Federal. Tema 793: responsabilidade solidária dos entes federados pelo dever de prestar assistência à saúde. Relator (voto vencedor): Min. Edson Fachin. Diário da Justiça, Brasília, [23 maio] 2019.

BUCCl, Maria Paula Dallari. Direito administrativo e políticas públicas. São Paulo: Saraiva, 2002.

BUCCI, Maria Paula Dallari. O conceito de política pública em direito. In: BUCCl, Maria Paula Dallari (org.). Políticas públicas: reflexões sobre o conceito jurídico. São Paulo: Saraiva, 2006.

BUCCl, Maria Paula Dallari. Contribuição para a redução judicialização da saúde. Uma estratégia jurídico-institucional baseada na abordagem de direito e políticas públicas. In: BUCCI, Maria Paula Dallari; SEIXAS, Clarice (org.). Judicialização da saúde: a visão do Executivo. São Paulo: Saraiva, 2017, p.31-88.

CONSELHO NACIONAL DE JUSTIÇA (Brasil); INSPER. INSTITUTO DE ENSINO E PESQUISA. Judicialização da saúde no Brasil: perfil das demandas, causas e propostas de solução. Brasília, 2019. Disponível em: https://www.cnj.jus.br/wp-content/uploads/conteudo/arquivo/2019/03/ f74c66d46cfea933bf22005ca50ec915.pdf. Acesso em: 24 maio 2021.

CONSELHO NACIONAL DE JUSTIÇA (Brasil). Justiça em números:

sumário executivo. Brasília, 2020. Disponível em: https://www.cnj.jus.br/ wp-content/uploads/2020/08/WEB_V2_SUMARIO_EXECUTIVO_CNJ_ JN2020.pdf. Acesso em: 25 nov. 2020.

CUSTÓDIO, André Viana; DABULL, Matheus Silva. Estado contemporâneo e políticas públicas: a efetivação dos direitos humanos fundamentais de crianças e adolescentes. In: CUSTÓDIO, André Viana; COSTA, Marli Marlene Moraes; STAHLHÖFER, lásin Schäffer (org.).

Direitos humanos, constituição e políticas públicas. Curitiba: Multideia, 2013.

GEBRAN, João Pedro, DRESCH, Renato Luís. A responsabilidade solidária e subsidiária dos entes políticos nas ações e serviços de saúde. Revista do Tribunal Regional Federal da Quarta Região, Porto Alegre, v. 25, n. 84, p. 77-103, 2015. Disponível em: https://www.trf4.jus.br/trf4/ controlador.php?acao=pagina_visualizar\&id_pagina=1972. Acesso em: 24 maio 2021. 
INSPER - INSTITUTO DE ENSINO E PESQUISA. Judicialização da saúde dispara e já custa R\$ 1,3 bi à União. São Paulo, 24 maio 2019. Disponível em: https://www.insper.edu.br/conhecimento/direito/judicializacao-dasaude-dispara-e-ja-custa-r-13-bi-a-uniao/. Acesso em: 24 maio 2021.

ONU - ORGANIZAÇÃO DAS NACCÕES UNIDAS. The concentration of income at the top of Brazil. Brasília: Nações Unidas do Brasil, 2017. Disponivel em: http://www.ipcig.org/pub/eng/WP163_The concentration_of_income_at_the_top_in_Brazil.pdf. Acesso em: $10 \mathrm{fev}$. 2021.

RAMOS, Elival da Silva. Ativismo judicial: parâmetros dogmáticos [recurso eletrônico]. 2. ed. São Paulo: Saraiva, 2015.

SADEK, Maria Tereza. Judiciário: mudanças e reformas. Estudos

Avançados, São Paulo, v. 18, n. 51, p. 79-101, maio-ago 2004.

Disponível em: https://www.scielo.br/scielo.php?script=sci_ arttext\&pid=S0103-40142004000200005. Acesso em: 16 out. 2020.

SANTOS, Boaventura Sousa. Introdução à sociologia da administração da justiça. Revista Crítica de Ciências Sociais, Coimbra, n. 21, p. 11-44, nov. 1986. Disponível em: http://www.boaventuradesousasantos.pt/ media/pdfs/Introducao_a_sociologia_da_adm_justica_RCCS21.PDF. Acesso em: 10 abr. 2021.

SANTOS, Lenir; TERRAZAS, Fernanda. Judicialização da saúde no Brasil. Campinas: Saberes Editora, 2014.

SILVA, Paulo Eduardo Alves da. Por um acesso qualitativo à justiça - o perfil da litigância nos Juizados Especiais Cíveis. Revista da Faculdade de Direito da UFMG, Belo Horizonte, n. 75, p. 443-466, jul./dez. 2019. Disponivel em: https://www.direito.ufmg.br/revista/index.php/revista/ article/view/2037. Acesso em: 2 mar. 2021.

VENTURA, Miriam. SIMAS, Luciana; PEPE, vera Lucia; SCHRAMM, Fermin. Judicialização da saúde, acesso à justiça e a efetividade do direito à saúde. Physis: Revista da Saúde Coletiva, Rio de Janeiro, n. 20, p. 77-100, 2010. Disponível em: https://www.scielo.br/scielo. php?script=sci_arttext\&pid=S0103-73312010000100006. Acesso em: 2 fev. 2021. 